\title{
COBERTURA DA TERRA E QUALIDADE AMBIENTAL DA BACIA HIDROGRÁFICA DO CÓRREGO VILA PINHEIROS, CURITIBA, PARANÁ (BRASIL)
}

\author{
Gabriela Muller Gouvea \\ Bacharela em Geografia \\ Universidade Federal do Paraná - UFPR \\ gabrielamullergouvea@hotmail.com \\ João Carlos Nucci \\ Professor Titular do Departamento de Geografia e do Programa de Pós-Graduação em Geografia \\ Universidade Federal do Paraná - UFPR \\ jenucci@gmail.com \\ Eduardo Liberti \\ Mestre em Geografia pelo Programa de Pós-Graduação em Geografia \\ Universidade Federal do Paraná - UFPR \\ eduardoliberti@hotmail.com
}

\begin{abstract}
RESUMO
A fragmentação e supressão das áreas com vegetação e o aumento das superfícies impermeabilizadas nas cidades colaboram para uma diminuição da qualidade ambiental. O objetivo do estudo foi avaliar a qualidade ambiental da bacia do Córrego Vila Pinheiros, localizada em Curitiba/Paraná (Brasil), com base na cobertura da terra. Foram utilizadas imagens orbitais disponibilizadas pelo Google Earth Pro e Google Street View, ano 2018, nas escalas 1:3.000 e 1:5.000, utilizando-se a quadra como área mínima. O mapeamento foi feito de maneira não automática no software ArcGis, e, posteriormente, foram analisadas as dinâmicas ambientais da bacia, gerando o mapa de qualidade ambiental. Constatou-se que $66,19 \%\left(0,98 \mathrm{~km}^{2}\right)$ da bacia são constituídos por espaços edificados, sendo que as edificações de até 4 pavimentos com vegetação nas áreas adjacentes ocupam 46,62\% $(0,69$ $\left.\mathrm{km}^{2}\right)$ da bacia. Os melhores níveis de qualidade ambiental representam 4,04\% $\left(0,06 \mathrm{~km}^{2}\right)$ do total da área estudada e são constituídos por espaços não edificados e com vegetação nos estratos arbustivos e/ou herbáceo e solo exposto. Os piores índices de qualidade ambiental da bacia concentram-se nas regiões sudeste, leste e nordeste e representam cerca de 4,05\% $\left(0,06 \mathrm{~km}^{2}\right)$ da área total. Esses dados apontam para uma baixa qualidade ambiental na bacia estudada.
\end{abstract}

Palavras-chave: Ecologia urbana. Planejamento da paisagem. Políticas públicas. Recursos hídricos.

\section{LAND COVER AND ENVIRONMENTAL QUALITY OF THE VILA PINHEIROS WATERSHED, CURITIBA, PARANÁ (BRAZIL)}

\begin{abstract}
The fragmentation and suppression of vegetated areas and the increase in waterproofed areas in cities contribute to a decrease in environmental quality. The objective of the study was to assess the environmental quality of the Vila Pinheiros watershed, located in Curitiba/Paraná, based on land cover. Orbital images provided by Google Earth Pro and Google Street View, the year 2018, were used, on the scales 1:3.000 and 1:5.000, using the court as the minimum area. The mapping was done in a non-automatic way in the ArcGis software, and, subsequently, the environmental dynamics of the basin were analyzed, generating the environmental quality map. It was found that most of the basin consists of builtup spaces $\left(66.19 \%, 0.98 \mathrm{~km}^{2}\right)$, with buildings with up to 4 floors with vegetation in the adjacent areas $\left(46.62 \%, 0.69 \mathrm{~km}^{2}\right)$. The best levels of environmental quality represent $4.04 \%(0.06$ $\mathrm{km}^{2}$ ) of the total area studied, are composed of no-built spaces with shrub and herbaceous vegetation, and exposed soil. The worst environmental quality indexes in the basin are concentrated in the southeast, east, and northeast regions, representing about $4.05 \%(0.06$ $\mathrm{km}^{2}$ ) of the total area. These data point to low environmental quality in the studied basin.
\end{abstract}

Keywords: Urban ecology. Landscape planning. Public policies. Water resources. 


\section{INTRODUÇÃO}

O rápido crescimento das cidades e de suas populações, por vezes visto como sinônimo de desenvolvimento econômico, associado a um planejamento urbano ineficiente, tem causado consideráveis alterações na paisagem, trazendo como consequências uma sucessão de problemas, contribuindo, assim, para a baixa qualidade ambiental urbana.

No meio urbano os problemas ambientais se tornam mais evidentes, sendo possível observar as maiores concentrações de poluentes no ar, na água e a degradação do solo, que são resultados direto de uma intensiva utilização da terra pelas atividades urbanas (LOMBARDO, 1985).

Dentre os fatores causadores de problemas ambientais urbanos, podem-se destacar, por exemplo, o aumento dos espaços edificados e a fragmentação e até supressão da vegetação nas cidades, além da existência de uma complexa infraestrutura para o funcionamento da paisagem urbana; essas situações ocasionam alterações no microclima e no ciclo hidrológico, promovendo uma diminuição da infiltração das águas pluviais, aumento do escoamento superficial e da amplitude térmica, degradação da qualidade do ar, da água e do solo, entre outros problemas relacionados com os tipos de uso e de cobertura da terra (LOMBARDO, 1985; SPIRN, 1995; MOTA, 1999; NUCCI, 2008; TONETTI, 2011; VALASKI, 2013, NUCCl et al., 2019).

Pauleit e Breuste (2011) destacam que o uso e a cobertura da terra são componentes importantes que entram na composição da estrutura das paisagens, interferindo em suas dinâmicas e, consequentemente, em suas qualidades. Assim, torna-se fundamental compreender como se distribuem os variados tipos de uso e cobertura da terra nas cidades, bem como suas dinâmicas, principalmente nas cidades que continuam se expandindo em termos de tamanho de população, número e extensão territorial (CADENASSO; PICKETT; SCHWARZ, 2007; VALASKI, 2013). Para Valaski (2013), as diferentes estruturas presentes na paisagem urbana possuem dinâmicas singulares que são capazes de fornecer benefícios e impor limitações para a ocupação humana.

Cadenasso et al. (2007) explicam a diferença entre uso da terra (land use) e cobertura da terra (land cover $)^{1}$, sendo o uso da terra definido pela utilização, enquanto que o termo cobertura da terra seria definido conforme o padrão físico, levando em consideração a heterogeneidade estrutural.

Uma contribuição para se compreender como se distribuem espacialmente as estruturas relacionadas com a cobertura da terra e sua relação com a qualidade ambiental urbana, pode ser encontrada na classificação proposta por Valaski (2013) e adaptada por Nucci; Ferreira e Valaski (2014). Essa contribuição teve como base os estudos de Nucci $(2001 ; 2008)$, no qual as inferências sobre a qualidade ambiental se fundamentaram em uma ampla revisão bibliográfica de autores como Marcus e Detwyler (1972), Douglas (1983), Sukopp e Werner (1991), Cavalheiro (1991), Spirn (1995), Hough (1998), dentre outros, que trabalham sob a perspectiva de bases teóricas relacionadas ao Planejamento da Paisagem, Ecologia da Paisagem e Ecologia Urbana, analisando, por exemplo, os efeitos da urbanização para a qualidade do ar, da água, do solo, da vegetação, flora e da fauna.

O Planejamento da Paisagem, baseado na Ecologia da Paisagem, é previsto legalmente na Alemanha como um instrumento central de planejamento para a preservação e conservação da natureza, onde sua principal meta, de acordo com Kiemsted et al. (1998), consiste em salvaguardar a capacidade funcional dos ecossistemas e a forma das paisagens de um modo sustentável e duradouro, mesmo em áreas urbanizadas. Heiland (2010) afirma que o Planejamento da Paisagem é um instrumento comprovado para assegurar alta qualidade ambiental.

Em relação a aplicação da classificação proposta por Valaski (2013) e adaptada por Nucci, Ferreira e Valaski (2014), podem ser citados, por exemplo, os trabalhos desenvolvidos por Dias, Nucci e Valaski (2014), Nucci, Ferreira e Valaski (2014), Costa, Nucci e Valaski (2015), Paz, Nucci e Valaski (2015) e Liberti e Nucci, (2017), que avaliaram diferentes bairros de Curitiba, cidade que obteve um notório reconhecimento, sobretudo a partir da década de 1970, por suas políticas públicas voltadas para o planejamento urbano, inclusive conquistando controversas denominações como "Cidade Modelo" e "Cidade Ecológica" (OLIVEIRA, 2000), mas que evidenciaram vários problemas ambientais.

${ }^{1} \mathrm{O}$ termo usual na literatura brasileira é "uso do solo", principalmente em estudos de áreas urbanas, mas na língua inglesa o termo usual é "land use" e não "soil use". Em paisagens não urbanizadas é comum a utilização dos termos uso e cobertura da terra, como em Braz et al. (2020). Neste trabalho optou-se por também utilizar os termos "uso da terra" (land use) e "cobertura da terra" (land cover).

Caminhos de Geografia Uberlândia-MG v. 22, n. 80

abr./2021

p. $153-168$

Página 154 
Diferentemente dos estudos citados, que analisaram a qualidade ambiental em bairros do município de Curitiba, a pesquisa em questão buscou compreender a dinâmica das estruturas que compõem a paisagem utilizando-se a bacia hidrográfica como recorte espacial, pois, segundo Fávero (2007), além das bacias constituírem um sistema natural notadamente delimitadas no espaço, visto que são definidas com base e critérios geomorfológicos, elas constituem-se como um importante critério e unidade territorial para o planejamento e gestão ambiental.

A bacia hidrográfica é uma unidade espacial tradicional nos estudos geográficos sobre o meio físico, e, desde as últimas décadas do século passado, ela vem sendo incorporada como unidade de estudo por outras áreas do conhecimento chamadas de ciências ambientais (BRAZ, et al. 2020).

Assim, o estudo analisou a distribuição espacial das estruturas que compõem a paisagem da bacia hidrográfica do Córrego Vila Pinheiro (Curitiba/Paraná) e sua relação com a qualidade ambiental, que, por ser uma bacia urbana, sofre diversos desequilíbrios ambientais, decorrentes, dentre outros, do alto índice de espaços edificados, inclusive com ocupações irregulares nas margens dos cursos d'água e percentuais muito baixos de espaços não edificados, sobretudo contendo vegetação.

A escolha, como recorte espacial de estudo, de uma bacia hidrográfica em uma paisagem altamente urbanizada, pretende chamar a atenção para os problemas do meio físico e valorizar os possíveis serviços ecossistêmicos existentes na cidade, apesar do dilema apontado por Beichler et al. (2017) e aprofundado por Tan et al. (2020), sobre a impossibilidade até de a cidade ser considerada como um ecossistema.

Além disso, estudos urbanos do meio físico, realizados em escalas de detalhe, valorizam o cotidiano do cidadão e podem funcionar como um incentivo para a sua participação no planejamento e gestão junto aos órgãos governamentais.

\section{METODOLOGIA}

A bacia hidrográfica do Córrego Vila Pinheiros se localiza na parte sul do município de Curitiba/Paraná, e abrange parte dos bairros Pinheirinho e Capão Raso, compreendendo uma área de aproximadamente $1,48 \mathrm{~km}^{2}$ (FIGURA 1).

Figura 1 - Bacia hidrográfica do Córrego Vila Pinheiros, Curitiba/Paraná, 2019.

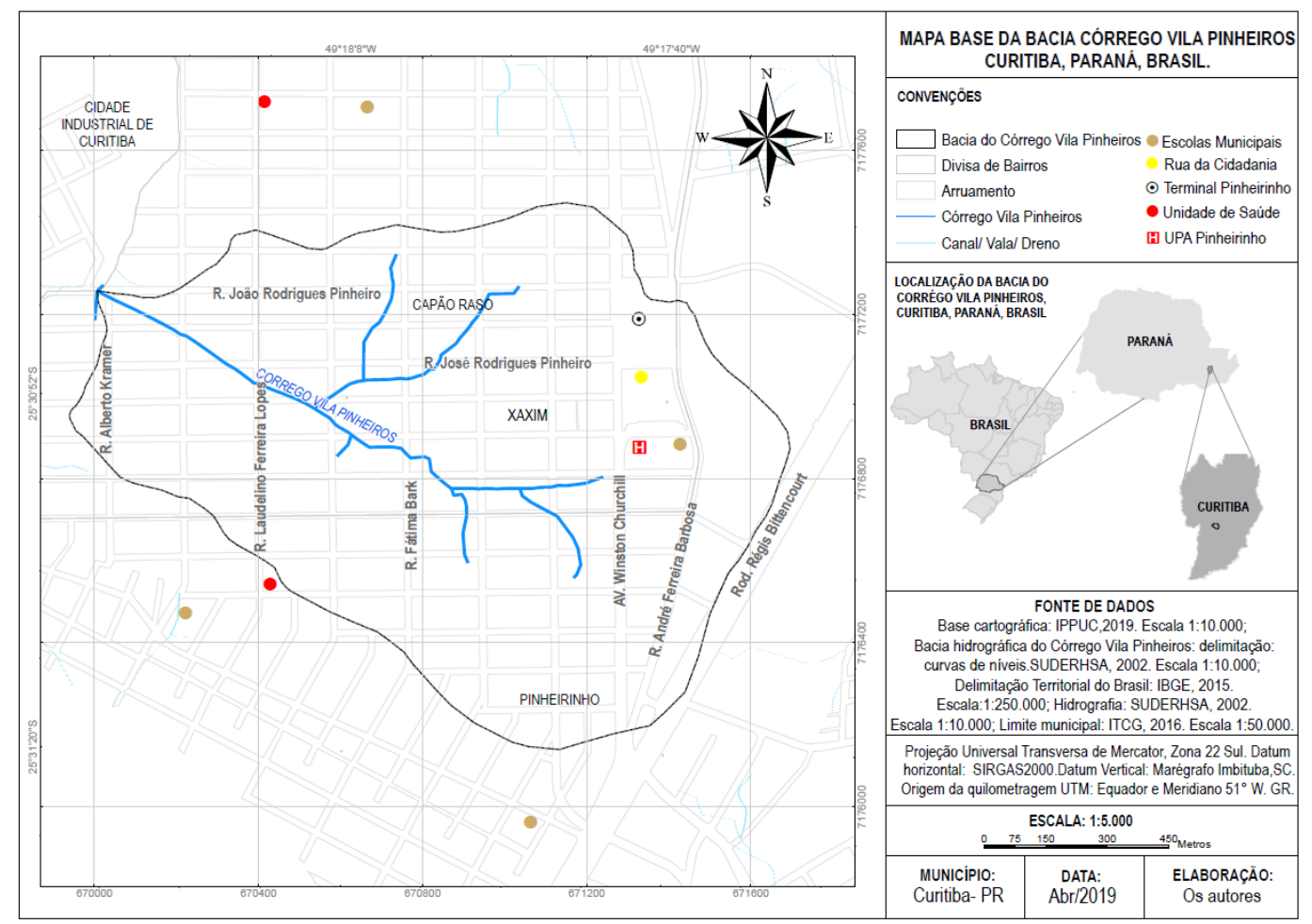

Fonte - Autores, 2019. 
As águas do córrego Vila Pinheiros, e de seus afluentes, correm quase que totalmente dentro de canalizações enterradas que passam por baixo das quadras e ruas da bacia. O córrego deságua em um outro córrego (sem nome identificado), que desemboca no rio Barigui que, por sua vez, deságua no rio Iguaçu, no extremo sul do município de Curitiba. O local de deságue no rio Barigui é considerado como área sujeita à inundação de acordo com IPPUC (2001).

Para a elaboração da base cartográfica, foram utilizados dados geoespaciais vetoriais em formato shapefile disponibilizados pelo Instituto de Pesquisa e Planejamento Urbano de Curitiba (IPPUC), ano 2019, escala 1:10.000. Utilizou-se como base para a delimitação da bacia, os arquivos vetoriais em formato shapefile referentes às curvas de nível e hidrografia, na escala 1:10.000, ano 2000, disponibilizados pelo Instituto das Águas do Paraná, antiga Superintendência de Desenvolvimento de Recursos Hídricos e Saneamento Ambiental (SUDERHSA).

O mapeamento de cobertura da terra foi realizado com base no método desenvolvido por Valaski (2013) e adaptado por Nucci; Ferreira; Valaski (2014), que se fundamenta nas características físicas da paisagem, verificando, por exemplo, se os lotes presentes nas quadras do ambiente urbano são constituídos por espaços edificados ou não, considerando o tamanho das edificações e o número de pavimentos, se há ou não a presença de vegetação e o porte das mesmas, além das características sobre a permeabilidade do solo (FIGURA 2).

Figura 2 - Legenda para a classificação da cobertura da terra.

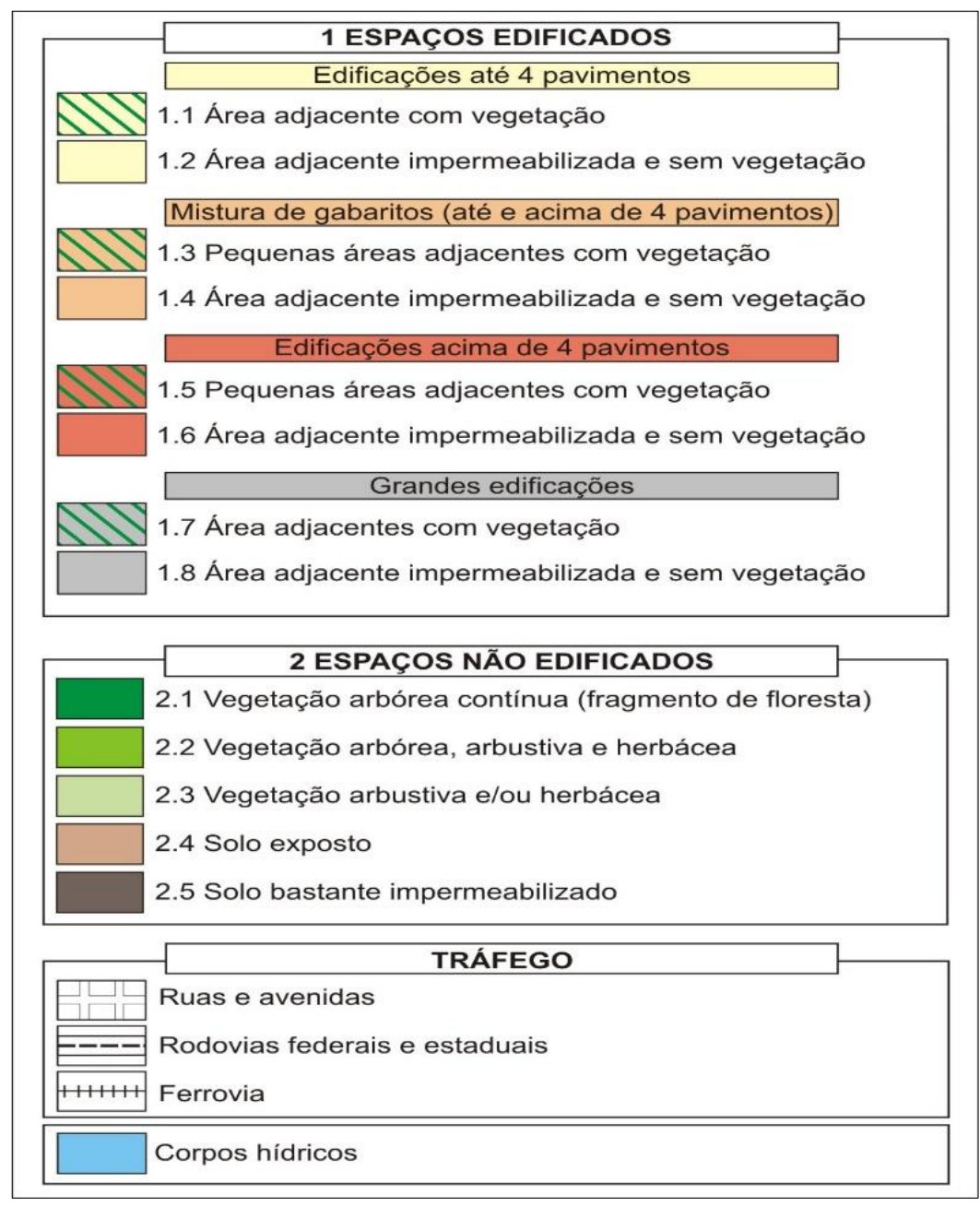

Fonte - Valaski (2013) e Nucci; Ferreira; Valaski (2014).

Com base nessa classificação (Figura 2), é possível realizar inferências sobre a qualidade ambiental do local, conforme figura 3.

Caminhos de Geografia Uberlândia-MG $\quad$ v. 22, n. $80 \quad$ abr./2021 $\quad$ p. 153-168 Página 156


Figura 3 - Qualidade Ambiental com base nas classes de cobertura da terra.

\begin{tabular}{|c|c|}
\hline \multirow{2}{*}{\begin{tabular}{c|c|} 
MELHOR \\
\end{tabular}} & $2.1+2.2$ - áreas cobertas por vegetação arbórea, arbustiva e herbácea \\
\hline & $2.3+2.4$ - áreas cobertas por vegetação arbustiva e/ou herbácea, solo exposto \\
\hline \multirow{3}{*}{ 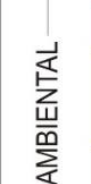 } & 1.1 - edificações de até 4 pavimentos e áreas adjacentes com vegetação \\
\hline & $\begin{array}{l}1.2+1.3 \text { - edificações de até } 4 \text { pavimentos, com área adjacente } \\
\text { impermeabilizada e sem vegetação ou mistura de gabaritos com edificações } \\
\text { acima e abaixo de } 4 \text { pavimentos e pequenas áreas adjacentes com vegetação }\end{array}$ \\
\hline & 2.5 - áreas com solo bastante impermeabilizado \\
\hline \multirow{4}{*}{ 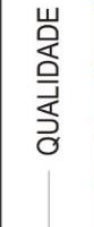 } & $\begin{array}{l}1.4 \text { - edificações até ou acima de } 4 \text { pavimentos (mistura de gabaritos) e com } \\
\text { área adjacente impermeabilizada e sem vegetação }\end{array}$ \\
\hline & 1.5 - edificações acima de 4 pavimentos com áreas adjacentes com vegetação \\
\hline & $\begin{array}{l}1.6 \text { - edificações acima de } 4 \text { pavimentos, com área adjacente impermeabilizada } \\
\text { e sem vegetação }\end{array}$ \\
\hline & 1.7 - grandes edificações com vegetação nas áreas adjacentes \\
\hline$\stackrel{\vec{P}}{\mathrm{PIOR}}$ & $\begin{array}{l}1.8 \text { - grandes edificações, com áreas adjacentes impermeabilizadas e sem } \\
\text { vegetação }\end{array}$ \\
\hline
\end{tabular}

Fonte - Valaski (2013) e Nucci, Ferreira e Valaski. (2014).

Para a interpretação da paisagem, foram utilizadas imagens orbitais disponibilizadas pelo Google Earth Pro, ano 2018, e Google Street View, ano 2018 com escalas entre 1:3.000 e 1:5.000. As classificações da cobertura da terra foram realizadas quadra a quadra na área de estudo, de maneira não automática, utilizando-se como auxílio o software ArcGis, versão 10.4.1.

\section{RESULTADOS E DISCUSSÃO}

A carta de cobertura da terra da bacia hidrográfica do Córrego Vila Pinheiros e os percentuais de cada classe em relação à área total da bacia podem ser observados nas figuras 4 e 5 .

Figura 4 - Cobertura da Terra da bacia hidrográfica do Córrego Vila Pinheiros - Curitiba, Paraná, Brasil.

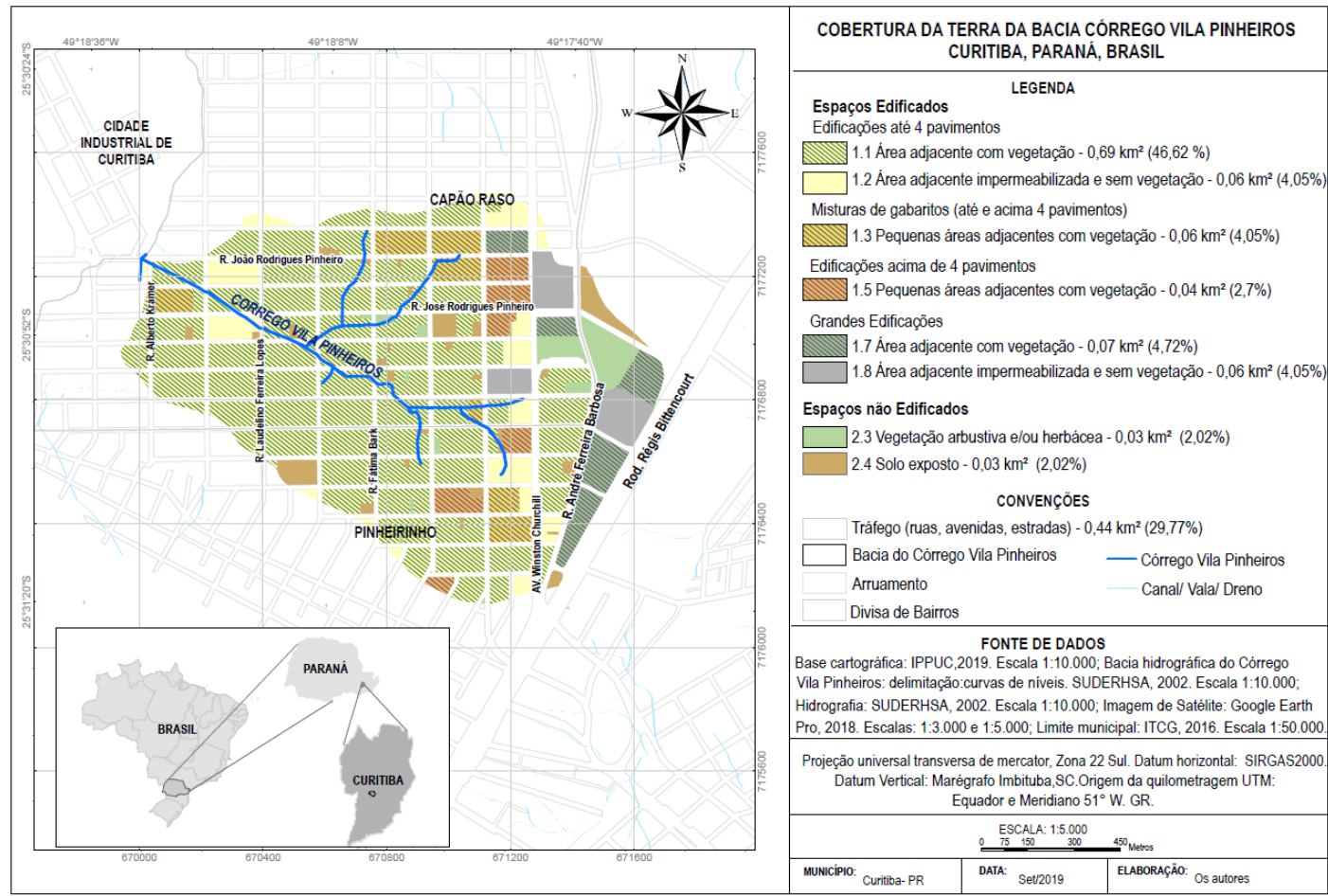

Elaboração - Autores, 2019. 
Figura 5 - Quantificação proporcional das classes de cobertura da terra da bacia hidrográfica do Córrego Vila Pinheiros - Curitiba/Paraná (valores em porcentagem).

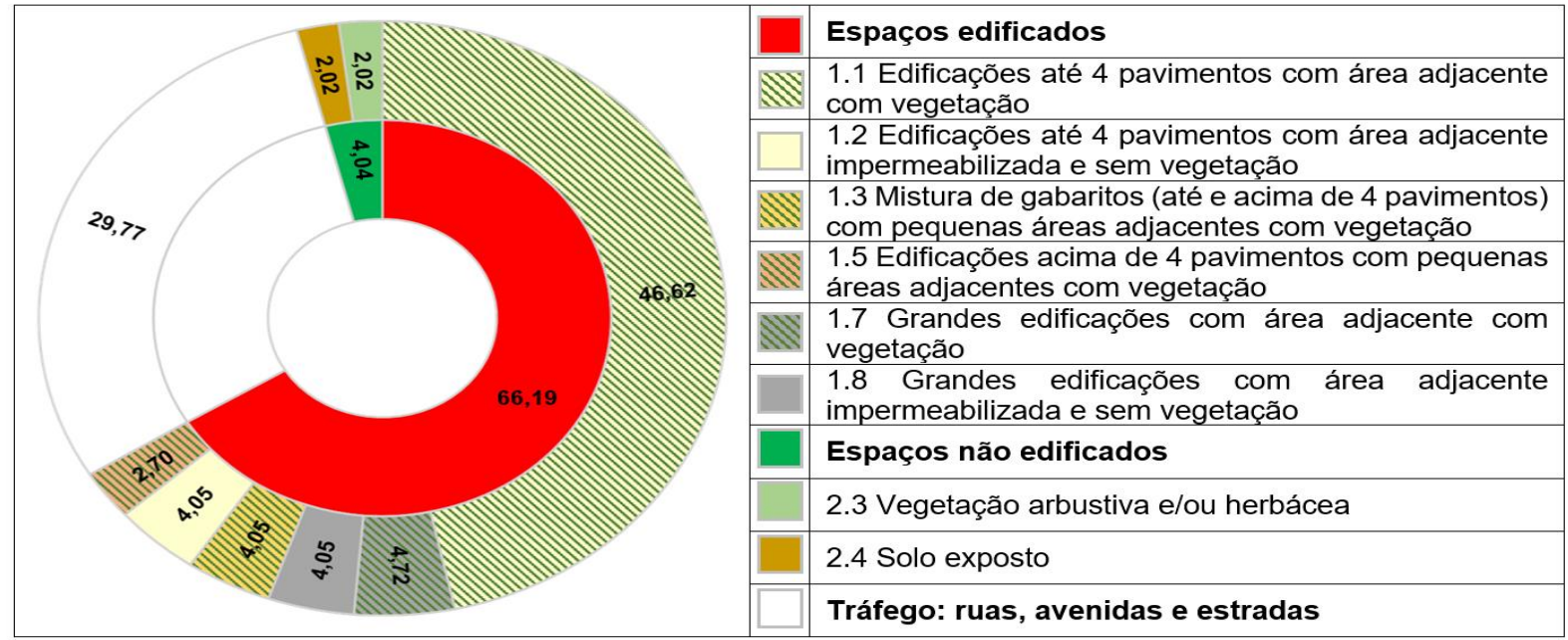

Elaboração - Autores, 2019.

Foram identificadas na bacia 8 dentre as 13 classes de cobertura da terra propostas no método utilizado (Figura 2). Assim, as classes 1.4 e 1.6, representadas pela mistura de gabaritos, com edificações até e acima de 4 pavimentos com áreas adjacentes impermeabilizadas e sem vegetação, não foram identificadas na área de estudo, bem como as classes 2.1, 2.2, e 2.5, referentes aos espaços não edificados contendo vegetação arbórea contínua, vegetação arbórea, arbustiva e herbácea e solo bastante impermeabilizado.

Dentre os espaços edificados, que constituem, aproximadamente, $66 \%\left(0,98 \mathrm{~km}^{2}\right)$ do total da área de estudo, a classe 1.1 , com cerca de $47 \%\left(0,70 \mathrm{~km}^{2}\right)$ do total da área, encontra-se distribuída espacialmente nas partes oeste, noroeste, centro e sudoeste da bacia do Córrego Vila Pinheiros.

Conforme o método utilizado, dentre os espaços edificados, a classe 1.1, referente as edificações de até 4 pavimentos com área adjacente com vegetação, é a que apresenta os melhores resultados relativos para a qualidade ambiental urbana. De acordo com Valaski (2013, p.107), algumas das inferências sobre a dinâmica ambiental neste tipo de estrutura são: "pouca infiltração da água da chuva; aumento do escoamento superficial; aumento da amplitude térmica; baixa emissão de poluentes na atmosfera e menor variedade de espécies da fauna".

Como a avaliação é feita de maneira relativa, ou seja, comparando-se as diferentes estruturas da paisagem e suas dinâmicas, admite-se que, mesmo apresentando aspectos que diminuam a qualidade ambiental, a classe 1.1 ainda se encontra em uma posição melhor do que, por exemplo, a classe 1.8, que se refere às grandes edificações com área adjacente impermeabilizada e sem vegetação, que representa a pior classe para a qualidade ambiental urbana.

$\mathrm{Na}$ área de estudo, a classe 1.8 representa cerca de $4 \%\left(0,06 \mathrm{~km}^{2}\right)$ do total da área da bacia e encontrase distribuída nas partes nordeste e sudeste. Dentre algumas das estruturas referentes a essa classe encontradas na bacia Vila Pinheiros, pode-se citar, por exemplo, alguns galpões com aspectos industriais e comerciais e um terminal rodoviário. Algumas das possíveis inferências sobre a dinâmica dessas estruturas são descritas por Valaski (2013) como:

"infiltração da água da chuva inexistente; grande escoamento superficial; alta amplitude térmica; alta emissão de poluentes na atmosfera pelo tráfego de veículos, incluindo de grande porte; quase inexistência de espécies da flora e fauna; alto gasto de energia para a manutenção das edificações" (VALASKI, 2013, p.108). 
As edificações de até 4 pavimentos com área adjacente impermeabilizada e sem vegetação, referente a classe 1.2, representa $4,05 \%\left(0,06 \mathrm{~km}^{2}\right)$ do total da área da bacia e se encontram distribuídas nas partes noroeste, sudoeste e sudeste. Uma das inferências sobre a dinâmica ambiental nessas estruturas aponta para a ocorrência de um alto escoamento superficial, visto que a infiltração das águas pluviais é quase inexistente, além de apresentar alta amplitude térmica (VALASKI, 2013).

Na mesma proporção da classe 1.2 em relação a área total da bacia, encontra-se a classe 1.3, referente a mistura de gabaritos, no qual encontram-se edificações até e acima de 4 pavimentos, contendo pequenas áreas adjacentes com vegetação, que estão distribuídas nas partes norte, noroeste e sulsudeste da área estudada.

Somando 2,7\% $\left(0,04 \mathrm{~km}^{2}\right)$ do total da área de estudo e localizando-se nas partes norte e sul da bacia Vila Pinheiros, encontram-se as edificações acima de 4 pavimentos com pequenas áreas adjacentes com vegetação, representada pela classe 1.5 da legenda.

Na figura 6 é possível observar exemplos de interpretação da paisagem por meio das imagens orbitais, nas quais descrevem a estrutura de cada classe de cobertura da terra.

Nas partes sudeste e leste da bacia encontram-se as estruturas referentes as grandes edificações com áreas adjacentes contendo vegetação, representada pela classe 1.7 da legenda. Com 4,72\% $\left(0,07 \mathrm{~km}^{2}\right)$ do total da área de estudo, essa classe corresponde ao segundo maior valor em termos quantitativos e configura-se, de maneira relativa, como a segunda estrutura com maior potencial para diminuir a qualidade ambiental.

As estruturas referentes aos espaços edificados com área adjacente impermeabilizada e sem vegetação apresentam características que conferem a paisagem urbana uma sucessão de problemas ambientais, trazendo como consequências a diminuição da qualidade ambiental. Segundo Lombardo (1985), dentre alguns dos problemas ambientais associados a essas estruturas, estão as alterações climáticas, como ilhas de calor, poluição atmostérica e chuvas cada vez mais intensas. Alterações no ciclo hidrológico correspondem a outro exemplo de problemas ambientais promovidos por essas estruturas, no qual o alto escoamento superficial das águas pluviais provocado pelas características impermeáveis do solo potencializam os riscos de enchentes, inundações e alagamentos (GONÇALVES e NUCCI, 2017).

Ao analisar a carta de cobertura da terra (Figura 4) e a hidrografia da bacia, observou-se que todos os cursos d'água, inclusive o córrego Vila Pinheiros, estão inseridos em espaços edificados, podendo-se inferir que as Áreas de Preservação Permanente (APP) encontram-se ocupadas e, dessa maneira, apresentam-se em conflito com a Lei Federal no 12.651 de 2012, que dispõe sobre a Proteção da Vegetação Nativa, em áreas urbana e rurais (BRASIL, 2012).

Os lotes representados por espaços não edificados e que apresentam vegetação nos portes arbustivo e/ou herbáceo (classe 2.3), somam pouco mais de $2 \%\left(0,03 \mathrm{~km}^{2}\right)$ do total da área estudada e estão localizados na parte leste da bacia. Essa classe consiste, de maneira relativa, na melhor estrutura para a qualidade ambiental urbana encontrada na área de estudo. De acordo com Valaski (2013), a vegetação presente nesses espaços colabora para que haja uma melhor infiltração das águas pluviais e, consequentemente, baixo escoamento superficial, além de baixa emissão de poluentes na atmosfera e maior variedade de espécies da flora e fauna.

Outra categoria relacionada aos espaços não edificados encontrada na área de estudo refere-se as áreas de solo exposto, que somam 2,02\% $\left(0,03 \mathrm{~km}^{2}\right)$ do total da área da bacia, mesma proporção das áreas que apresentam vegetação, estando distribuídas espacialmente nas partes sudoeste, sulsudeste, nordeste e na região central da bacia. 
Na figura 7 é possível observar exemplos de interpretação da paisagem por meio das imagens orbitais, nas quais descrevem a estrutura de cada classe de cobertura da terra.

Figura 6 - Imagens orbitais do Google Earth Pro e Google Street View das classes 1.1, 1.8, 1.2 e 1.3.

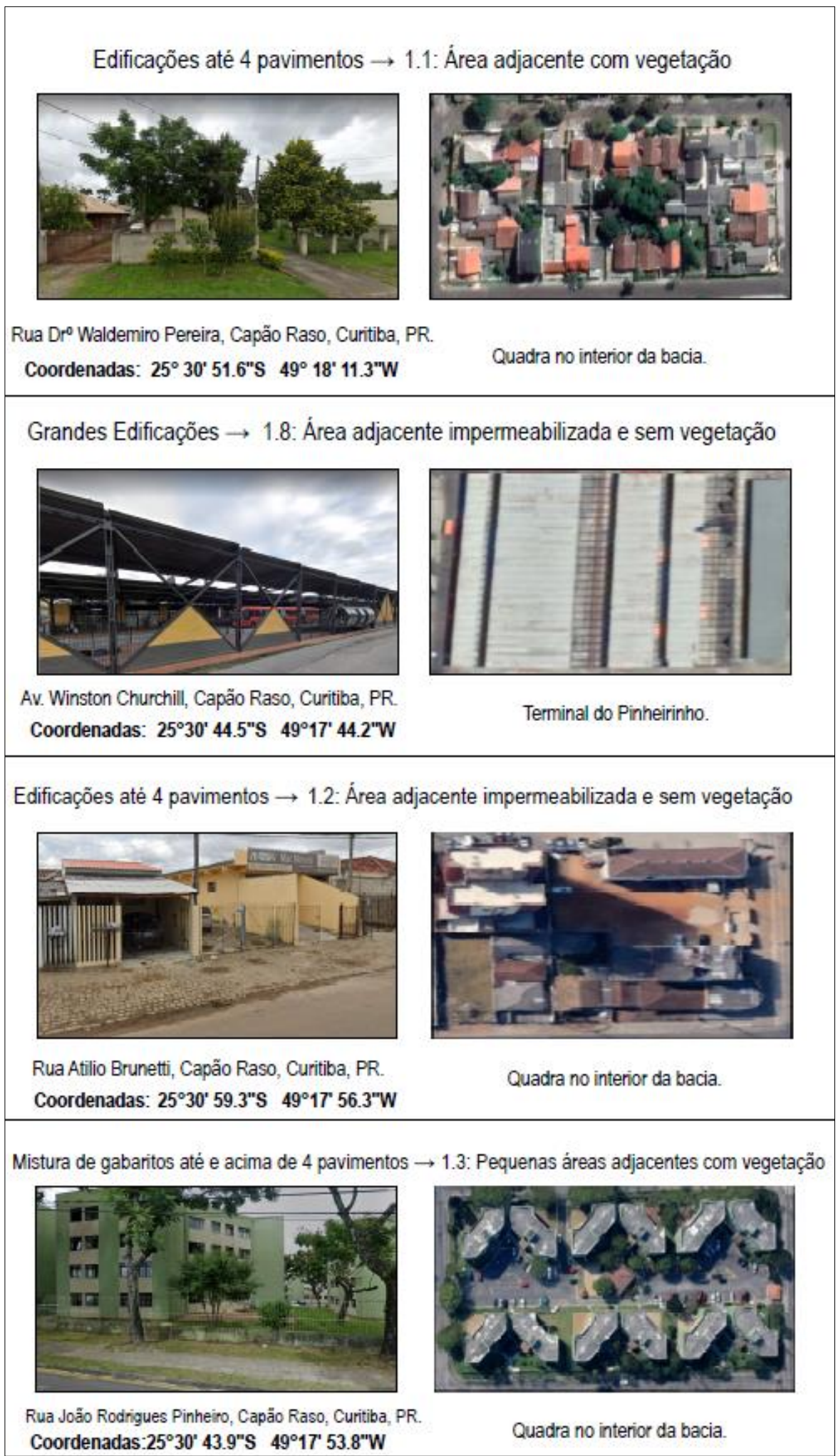

Fonte - Imagens de satélite - Google Maps, 2018 e Google Street View, 2018. Organização: Autores, 2020.

Caminhos de Geografia Uberlândia-MG v. 22, n. $80 \quad$ abr./2021 p. 153-168 Página 160


Figura 7 - Imagens orbitais do Google Earth Pro e Google Street View das classes 1.5, 1.7, 2.3 e 2.4.

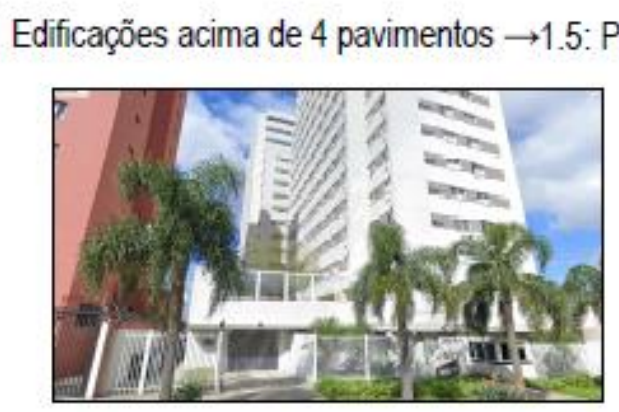

Rua Dro Waldemiro Pereira, Capão Raso, Curitiba, PR.

Coordenadas: $25^{\circ} 30^{\prime} 51.20^{\prime \prime} \mathrm{S} 49^{\circ} 17^{\prime} 47.97^{\prime \prime} \mathrm{W}$

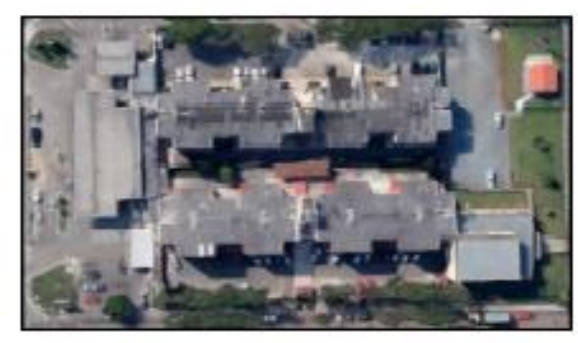

Quadra no interior da bacia
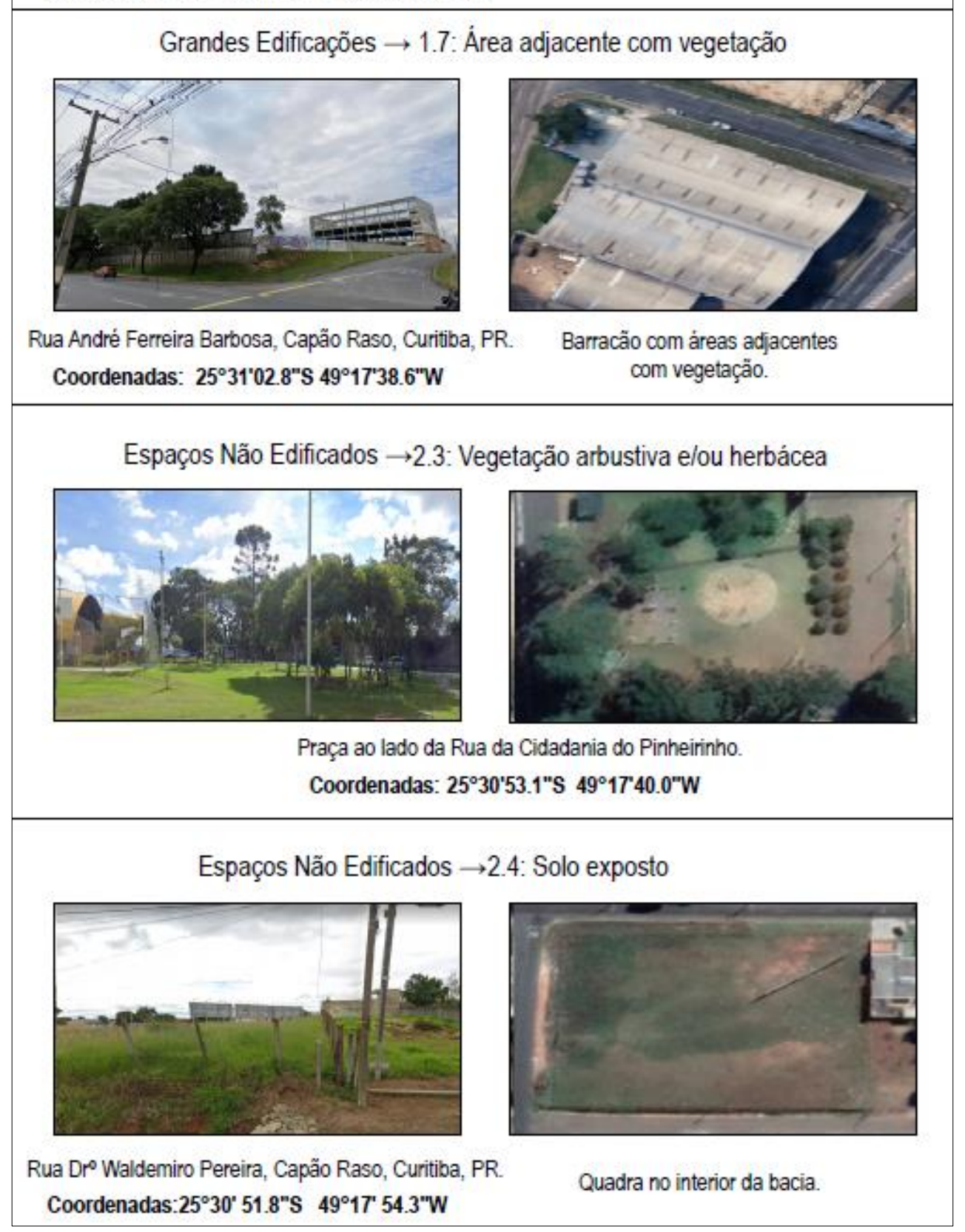

Fonte - Imagens de satélite - Google Maps, 2018 e Google Street View, 2018. Organização: Autores, 2020. 
As inferências espacializadas sobre as dinâmicas das classes de cobertura da terra identificadas (Figura 2) são apresentadas na Carta de Qualidade Ambiental. Essa carta procura traduzir, de um modo um pouco mais simplificado e relativo, as condições ambientais identificadas na bacia (Figura 8) e a figura 9 apresenta a quantificação proporcional dos dados.

Figura 8 - Qualidade Ambiental da bacia hidrográfica do Córrego Vila Pinheiros - Curitiba, Paraná, Brasil.

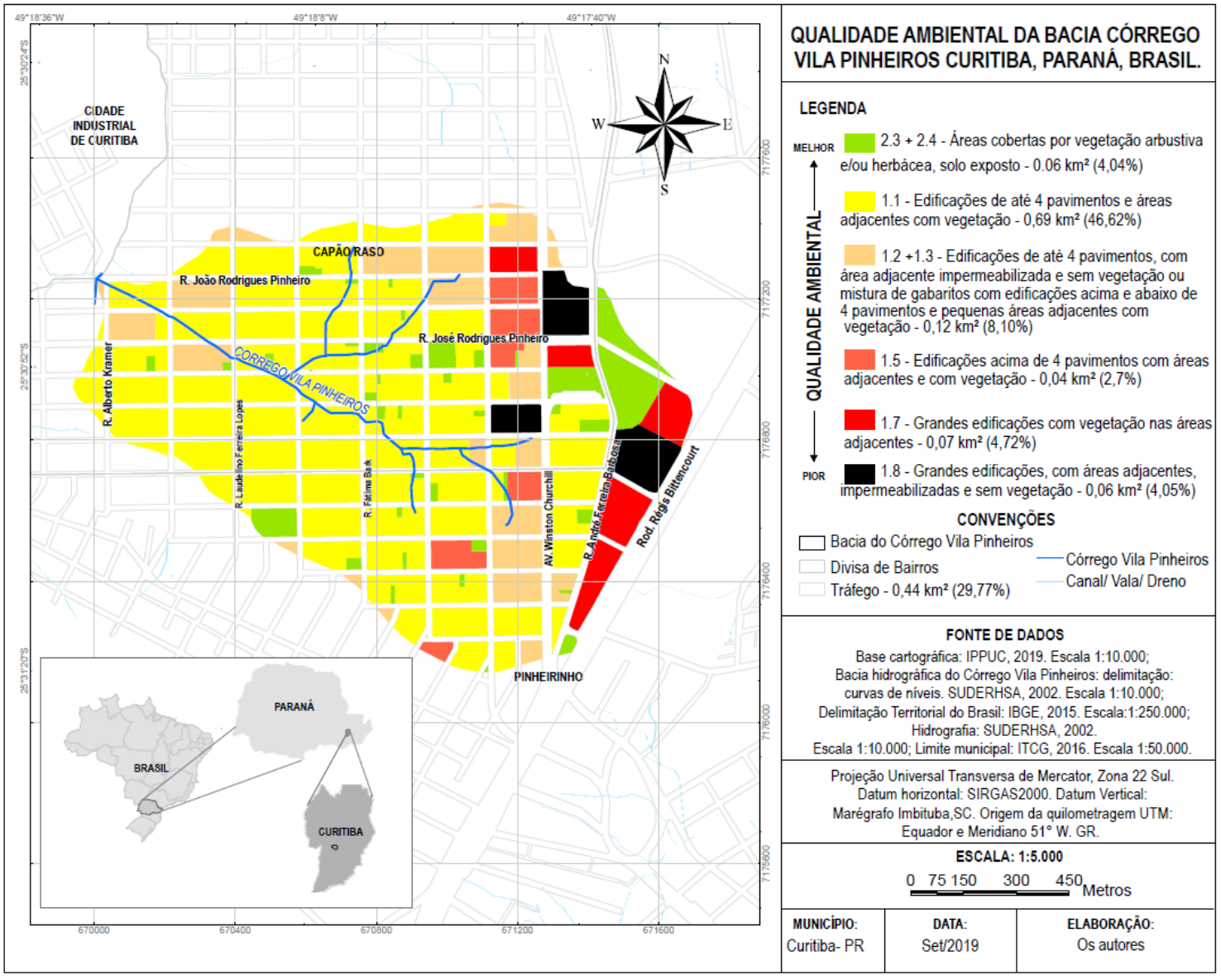

Elaboração - Autores, 2019.

Figura 9 - Quantificação proporcional das classes de cobertura da terra relacionadas com a qualidade ambiental da bacia hidrográfica do Córrego Vila Pinheiros - Curitiba/Paraná. (valores em porcentagem).

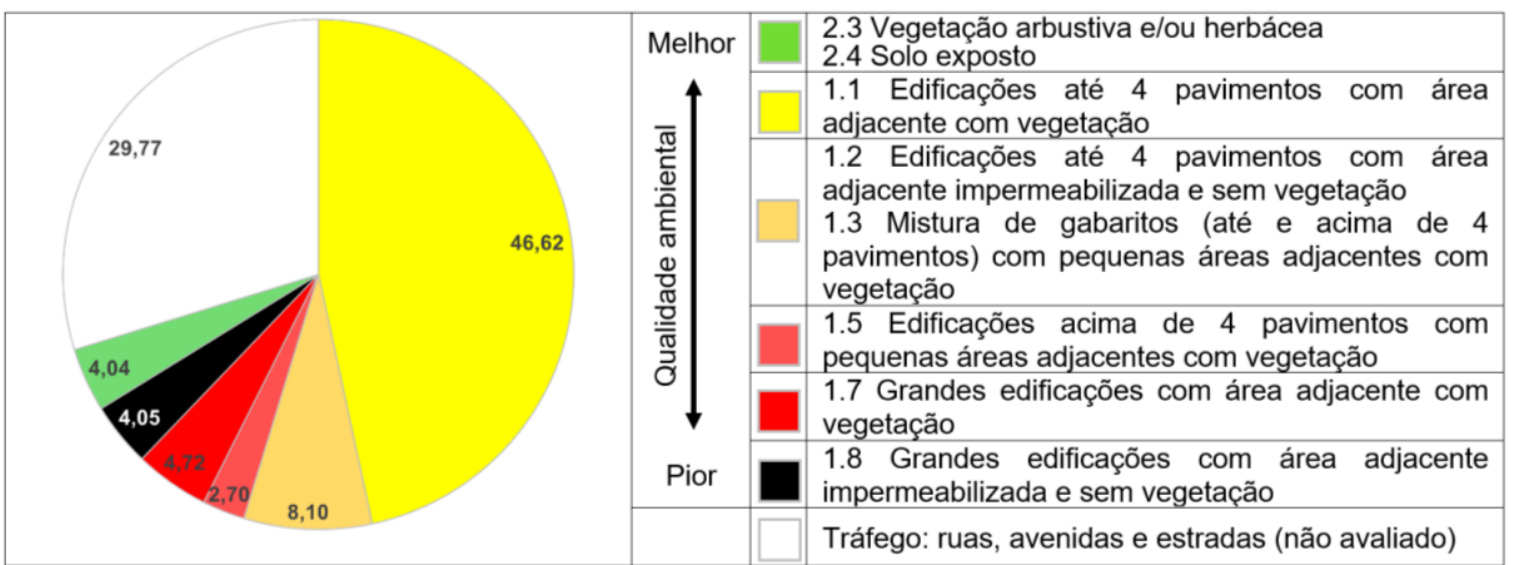

Elaboração - Autores, 2019. 
De modo geral, pode-se identificar na figura 8 que as áreas mais a leste, próximas à divisa com o bairro Xaxim e à rodovia Régis Bittencourt, são as que apresentam os piores níveis de qualidade ambiental, sendo essas as áreas que se encontram a montante das nascentes dos rios que constituem a bacia estudada. Esses piores níveis de qualidade ambiental são inferidos com base nas características estruturais evidenciadas pelas classes de cobertura da terra, ou seja, em síntese, superfícies muito impermeabilizadas por edificações e sem a presença de cobertura vegetal.

Além disso, as melhores estruturas para a qualidade ambiental consideradas no método utilizado, que seriam as referentes às classes 2.1 e 2.2 (vegetação arbórea contínua - fragmento de floresta e vegetação arbórea, arbustiva e herbácea, respectivamente), não foram encontradas na área de estudo, fato que contribui ainda mais para a baixa qualidade da bacia do córrego Vila Pinheiros.

As vias de tráfego, que representam quase $30 \%\left(0,44 \mathrm{~km}^{2}\right)$ do total da área da bacia e se inserem junto aos espaços não edificados, não são consideradas, pelo método utilizado, na análise sobre a qualidade ambiental urbana, portanto, aparecem identificadas apenas pela cor branca na figura 8, porém, sabese que esse tipo de cobertura da terra contribui muito para a impermeabilização da bacia.

Em um artigo de revisão, Boulton et al. (2018) explicam que não é fácil afirmar qual a quantidade de espaços verdes que uma cidade necessita e que tanto a falta quanto o excesso podem ser prejudiciais. No entanto, na literatura não é raro encontrar recomendações de índices mínimos de cobertura vegetal ou de áreas verdes por habitante, mas o difícil é descobrir qual o método utilizado para eleger esses índices (ROCHA e NUCCI, 2018).

Em termos comparativos, setores de planejamento da Alemanha, país referência nos estudos sobre o Planejamento da Paisagem, sugerem que $40 \%$ das áreas urbanas sejam destinadas para os espaços não edificados, $40 \%$ para os espaços edificados e $20 \%$ para os espaços de integração viária ( $\mathrm{NUCCl}$, 2008). No Atlas Ambiental de Berlim (BERLIM, 1995) estão dispostos dados de algumas cidades alemãs que respeitam essa sugestão, sendo que na média, essas cidades apresentam $47 \%$ de espaços não edificados, $39 \%$ de espaços edificados e $14 \%$ de espaços pertencentes ao sistema viário (Tabela 1).

Tabela 1 - Classificação e quantificação do uso da terra em algumas cidades da Alemanha. (valores aproximados e em porcentagem).

\begin{tabular}{|c|c|c|c|c|c|c|c|c|}
\hline Uso & Berlin & Hamburg & Munich & Cologne & Frankfurt & Hanover & Média & Média \\
\hline Água & 6 & 8 & 1 & 5 & 2 & 3 & 4 & \multirow{4}{*}{$\begin{array}{c}\text { Espaços } \\
\text { Não } \\
\text { edificados } \\
(47 \%)\end{array}$} \\
\hline Floresta & 18 & 4 & 5 & 14 & 15 & 11 & 11 & \\
\hline Agricultura & 7 & 30 & 18 & 22 & 28 & 19 & 21 & \\
\hline $\begin{array}{l}\text { Parque e } \\
\text { cemitério }\end{array}$ & 11 & 4 & 12 & 10 & 15 & 14 & 11 & \\
\hline Edificações & 43 & 34 & 40 & 32 & 25 & 33 & 35 & \multirow{2}{*}{$\begin{array}{c}\text { Espaços } \\
\text { Edificados } \\
(39 \%)\end{array}$} \\
\hline Misto & 3 & 8 & 7 & 2 & 0 & 6 & 4 & \\
\hline Sist. viário & 12 & 12 & 17 & 15 & 14 & 15 & 14 & $(14 \%)$ \\
\hline
\end{tabular}

Fonte - Berlim (1995); Pivetta, et al. (2005) e Dias et al. (2014).

Ao analisar os valores percentuais da bacia hidrográfica do Córrego Vila Pinheiros, observa-se que os resultados estão aquém da sugestão alemã. A tabela 2 apresenta uma comparação entre os valores percentuais da bacia do córrego Vila Pinheiros e de outros estudos realizados na cidade de Curitiba, que utilizaram o mesmo método, com os valores sugeridos na Alemanha. Nota-se que a maior parte 
das localidades estudadas apresenta valores piores em relação a sugestão alemã, sendo que os percentuais que mais se aproximam se referem aos do bairro Tatuquara, e os do município como um todo, indicando que algumas áreas do município de Curitiba apresentam melhor qualidade ambiental em relação à outras.

Tabela 2 - Comparação entre os percentuais sugeridos na Alemanha com trabalhos aplicados em Curitiba, Paraná, Brasil, utilizando-se o mesmo método (valores aproximados).

\begin{tabular}{|c|c|c|c|}
\hline Áreas Estudadas & $\begin{array}{c}\text { Espaços Edificados } \\
(\%)\end{array}$ & $\begin{array}{c}\text { Espaços não Edificados } \\
\text { (\%) }\end{array}$ & $\begin{array}{c}\text { Sistema Viário } \\
(\%)\end{array}$ \\
\hline Sugestão - Alemanha (1) & 40 & 40 & 20 \\
\hline Bacia Córrego Vila Pinheiros & 66 & 4 & 30 \\
\hline Bacia do Alto Belém (2) & 54 & 26 & 20 \\
\hline Bairro - Boa Vista (3) & 60 & 13 & 27 \\
\hline Bairro - Bacacheri (4) & 59 & 23 & 18 \\
\hline Bairro - Rebouças (5) & 69 & 3 & 28 \\
\hline Bairro - Bairro Alto (6) & 68 & 8 & 25 \\
\hline Bairro - Tatuquara (7) & 32 & 48 & 20 \\
\hline Bairro - Parolin (8) & 66 & 3 & 31 \\
\hline Município de Curitiba (9) & 49 & 38 & 13 \\
\hline
\end{tabular}

Fonte - (1) Nucci (2008); (2) Liberti e Nucci; (2019); (3) Paz, Nucci e Valaski (2015); (4) Dias, Nucci e Valaski (2014); (5) Nucci, Ferreira e Valaski (2014); (6) Costa, Nucci e Valaski (2015); (7) Paz, Nucci e Valaski (2015); (8) Liberti e Nucci, (2017); (9) Ferreira (2015). Organização: autores, 2020.

A constatação da baixa quantidade de espaços não edificados, sobretudo contendo vegetação, que somam apenas 2,2\% $\left(0,03 \mathrm{~km}^{2}\right)$ do total da área da bacia, bem como o alto percentual em relação aos espaços edificados, somando pouco mais de $66 \%\left(0,98 \mathrm{~km}^{2}\right)$ do total da área de estudo, representam um sinal de alerta, tanto para o poder público como para a população local, quanto à qualidade ambiental urbana.

De acordo com Nucci (2008), a vegetação no ambiente urbano, quando bem distribuída em termos quantitativos e qualitativos, desempenha uma função central na melhoria da qualidade ambiental, pois é com base nela que muitos problemas podem ser amenizados ou resolvidos.

Além disso, destaca-se, com base nos dados da tabela 2, que $96 \%\left(1,42 \mathrm{~km}^{2}\right)$, ou seja a soma dos espaços edificados com o sistema de espaços viários, da área da bacia podem ser considerados como superfícies impermeabilizadas, ou seja, a bacia contribui para o agravamento das áreas sujeitas à inundação localizadas à jusante, por não apresentar mecanismos que segurem, por um tempo, as águas pluviais que caem em seu interior.

Nesse sentido, visando melhorar a qualidade ambiental da bacia Vila Pinheiros, sugere-se medidas que visem a manutenção e ampliação das áreas vegetadas, sobretudo em relação aos espaços cobertos por vegetação arbustiva e/ou herbácea existentes na área de estudo. Para as áreas ocupadas por solo exposto, aconselha-se que sejam realizadas ações visando o reflorestamento com a utilização de vegetação nativa.

Recomenda-se que para as estruturas dos espaços edificados relacionados as classes 1.1, 1.3, $1.5 \mathrm{e}$ 1.7, sejam incentivados a manutenção, melhoria e ampliação da vegetação presente em suas áreas

Caminhos de Geografia $\quad$ Uberlândia-MG $\quad$ v. 22, n. $80 \quad$ abr./2021 $\quad$ p. 153-168 Página 164


adjacentes. Sugere-se para as edificações com as áreas adjacentes impermeabilizadas e que não apresentam parcelas vegetadas, que sejam estimulados o reverdecimento de fachadas, telhados, muros, recuos e quintais com a utilização de vegetação de porte herbáceo, arbustivo e/ou arbóreo. Além do reverdecimento, ações como o incentivo a instalação de cisternas ou outros mecanismos para captação e armazenamento das águas pluviais ou emprego de pavimentações permeáveis contribuiriam no controle das inundações e dos alagamentos, tais como os Sistemas de Drenagem Sustentável como sugerem Gonçalves e Nucci (2017).

\section{CONSIDERAÇÕES FINAIS}

A aplicação do método proposto por Valaski (2013) e adaptado por Nucci; Ferreira; Valaski (2014), permitiu de modo descomplicado a elaboração do mapeamento e a análise da cobertura da terra e da qualidade ambiental da bacia do Córrego Vila Pinheiros, Curitiba/Paraná e, como resultado constatouse que a bacia apresenta uma baixa qualidade ambiental devido à pouca presença de vegetação na área e o fato de não serem encontradas as classes 2.1, referente à vegetação arbórea contínua (fragmento de floresta), e a classe 2.2, referente à vegetação arbórea, arbustiva e herbáceas, essas as que mais colaboram para uma boa qualidade ambiental urbana.

As duas melhores classes referentes aos espaços não edificados estão distribuídas na parte noroeste, sudoeste e sudeste da bacia, representando uma pequena quantidade em relação a área total, apenas $4 \%\left(0,06 \mathrm{~km}^{2}\right)$, e tem como os piores índices de qualidade ambiental da bacia do Córrego Vila Pinheiros se concentram nas regiões sudeste e leste perto da Rodovia Régis Bittencourt.

O sistema dos espaços edificados é o que se destaca na bacia, representando $66,19 \%\left(0,98 \mathrm{~km}^{2}\right)$, o que traz riscos para a população residente por aumentar as chances de inundações e alagamentos quando há edificações com áreas adjacentes impermeabilizadas. Esses espaços somados aos 30\% $\left(0,44 \mathrm{~km}^{2}\right)$ de espaços viários, perfazem um grau de impermeabilização do solo da ordem de $96 \%(1,42$ $\mathrm{km}^{2}$ ) da área da bacia.

O método utilizado apresentou-se como uma importante ferramenta para a análise e planejamento das cidades. Além de ser um instrumento de fácil aplicação e entendimento, ele pode vir a auxiliar na elaboração, aplicação de políticas públicas ligadas ao Planejamento da Paisagem.

\section{REFERÊNCIAS}

BEICHLER, S. A.; BASTIAN, O., HAASE, D.; HEILAND, S.; KABISCH, N.; MÜLLER, F. Does the Ecosystem Service Concept Reach its Limits in Urban Environments? Landscape Online 51:1-21, 2017. Disponível em: https://doi.org/10.3097/LO.201751. Acesso em: 03 jul. 2020.

BERLIM. Senate Departament of Urban Development. Berlin Digital Environmental Atlas. Actual Use of Built-up Areas. (06.01 Uso real de áreas construídas / 06.02 Inventário de espaços verdes e abertos edição 1995), $1995 . \quad$ Disponível em: https://www.stadtentwicklung.berlin.de/umwelt/umweltatlas/ed601_05.htm\#Abb1. Acesso em: 04 jul. 2020.

BOULTON, C.; DEDEKORKUT-HOWES, A.; BYRNE, J. Factors shaping urban greenspace provision: A systematic review of the literature. Landscape and Urban Planning, v. 178, 2018, p. 82-101. Disponível em: https://doi.org/10.1016/j.landurbplan.2018.05.029. Acesso em: 04 jul. 2020.

BRASIL. Novo Código Florestal Brasileiro (Lei o 12.651, de 25 de maio de 2012). Disponível em: http://www.planalto.gov.br/ccivil_03/_Ato2011-2014/2012/Lei/L12651.htm. Acesso em: 16 fev. 2020.

BRAZ, A. M.; MIRANDOLA GARCIA, P. H.; PINTO, A. L.; SALINAS CHÁVEZ, E.; DE OLIVEIRA, I. J. Manejo integrado de cuencas hidrográficas: posibilidades y avances en los análisis de uso y cobertura de la tierra. Cuadernos de Geografía: Revista Colombiana de Geografía 29 (1):69-85, 2020 .Disponível em: https://doi.org/10.15446/rcdg.v29n1.76232. Acesso em: 03 jul. 2020. 
CADENASSO, M. L; PICKETT, S. T. A; SCHWARZ K. Spatial heterogeneity in urban ecosystems: reconceptualizing land cover and a framework for classification. Front Ecol Environ, Washington, v. 5, n. 2, p. 80-88, 2007. https://doi.org/10.1890/1540-9295(2007)5[80:SHIUER]2.0.CO;2

CAVALHEIRO, F. Urbanização e alterações ambientais. In: TAUK, S.M.; GOBBI, N.; FOWLER. H. G. Análise Ambiental: uma visão multidisciplinar. 1ed. São Paulo: UNESP, 1991, v. 1, p. 88-99.

COSTA, P. H.; NUCCI, J. C.; VALASKI, S. A I. A Cobertura da Terra e a Qualidade Ambiental Urbana do Bairro Alto (Curitiba-PR). Cidades Verdes, Curitiba, v. 03, p. 121-137, 2015. Disponível em: http://dx.doi.org/10.17271/23178604382015988. Acesso em: 16 set. 2019.

DIAS, M. A.; NUCCI, J. C.; VALASKI, S. Classificação da paisagem do bairro do Bacacheri (Curitiba, Paraná) com base na cobertura do solo. Ra'e $\mathbf{G a}-\mathbf{O}$ espaço geográfico em análise, Curitiba, $n^{\circ} \mathbf{3 2}$, p.146-163, 2014. Disponível em: https://revistas.ufpr.br/raega/article/view/36451. Acesso em: 17 set. 2019. https://doi.org/10.5380/raega.v32i0.36451

DOUGLAS, I. The urban environment. Londres, Edward Arnold (Publishers) Ltda, 1983, 229p.

FÁVERO, O. A. Paisagem e Sustentabilidade na Bacia Hidrográfica do Rio Sorocaba (SP). Tese (Doutorado em Geografia Humana) - Departamento de Geografia/FFLCH, Universidade de São Paulo, São Paulo. 2007, 330p. Disponível em: https://teses.usp.br/teses/disponiveis/8/8136/tde-11122007095647/publico/TESE_ORIANA APARECIDA FAVERO.pdf. Acesso em: 03 out. 2019.

FERREIRA, M. B. P. Cobertura da terra como indicador de qualidade ambiental urbana: estudo aplicado ao município de Curitiba-PR. Dissertação (Mestrado em Geografia) - Setor de Ciências da Terra, Universidade Federal do Paraná, Curitiba, 2015, 82p. Disponível em: https://acervodigital.ufpr.br/bitstream/handle/1884/38333/R\%20-\%20D\%20-

\%20MANOELLA\%20BARROS\%20PEDREIRA\%20FERREIRA.pdf?sequence=3\&isAllowed=y. Acesso em: 27 set. 2019.

GONÇALVES, F.T.; NUCCI, J.C. Sistemas de Drenagem Sustentável (SUDs): propostas para a bacia do rio Juvevê, Curitiba-PR. RAEGA, 42, 2017, 192-209. Disponível em: https://revistas.ufpr.br/raega/article/view/47043/34143. Acesso em: 15 dez. 2020. https://doi.org/10.5380/raega.v42i0.47043

HEILAND, S. Landschaftsplanung. In: Henckel, D.; von Kuczkowski, K.; Lau, P.; Pahl-Weber, E.; Stellmacher, F. (Hrsg.) Planen - Bauen - Umwelt. Ein Handbuch. Wiesbaden. S. p. 294-300, 2010.

HOUGH, M. Naturaleza y Ciudad. Planificación Urbana y Processos Ecológicos. Barcelona: Editora Gustavo Gili, 1998.

IPPUC. Instituto de Pesquisa e Planejamento Urbano de Curitiba. Mapa de Áreas Inundáveis no Município de Curitiba. 2001.2 Disponível em: https://ippuc.org.br/mostrarpagina.php?pagina=353\&idioma=1\&ampliar=n\%E3o\#fisicos Acesso em: 15 nov. 2019.

KIEMSTEDT, H.; HAAREN, C; MÖNNECKE, M; OTT, S. Landscape Planning. Contents and Procedures. Bonn: Federal Ministry for the Environment, Nature Conservation and Nuclear Safety, 1998, 39p.

LIBERTI, E.; NUCCI, J. C. Cobertura da terra e qualidade ambiental urbana na bacia hidrográfica do Alto Belém - Curitiba/Paraná. In: XIII ENANPEGE - A Geografia Brasileira na Ciência-Mundo: produção, circulação e apropriação do conhecimento, 2019, São Paulo. Anais... ENANPEGE. São Paulo: USP -

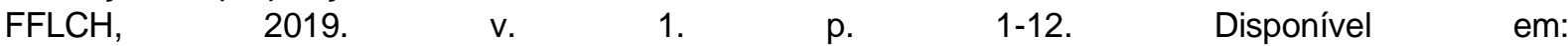
https://www.enanpege2019.anpege.ggf.br/resources/anais/8/1562345440_ARQUIVO_liberti_nucci_en anpege_NOVO.pdf. Acesso em: 20 abr. 2020.

Uso e Cobertura da Terra: Avaliação da Qualidade Ambiental do Bairro Parolin, Curitiba/Paraná. Espaço e Geografia, Brasília, v. 20, n. 1, p. 179-200, 2017. Disponível em: http://www.Isie.unb.br/espacoegeografia/index.php/espacoegeografia/article/view/423/285. Acesso em: 26 set. 2019.

LOMBARDO, M. A. Ilha de calor nas metrópoles: o exemplo de São Paulo. São Paulo: Hucitec, 1985.

Caminhos de Geografia $\quad$ Uberlândia-MG $\quad$ v. 22, n. $80 \quad$ abr./2021 p. 153-168 Página 166


MARCUS, M. G.; DETWYLER, T. R. Urbanization and environment. Bermont/Cal., Duxburg Press, 1972, 286p.

MOTA, S. Urbanização e meio ambiente. Rio de Janeiro: ABES (Associação Brasileira de Engenharia Sanitária e Ambiental), 1999, 352p.

NUCCI, J. C.; VALASKI, S.; ESTÊVEZ, L. F.; TONETTI, E. L. Uso da terra e qualidade ambiental urbana: uma proposta de legenda para mapeamento. GEOgraphia, v. 21, n. 46, 2019. Disponível em: https://periodicos.uff.br/geographia/article/view/14390 Acesso em: 04 jul. 2020. https://doi.org/10.22409/GEOgraphia2019.v21i46.a14390

NUCCI, J. C.; FERREIRA, M. B. P.; VALASKI, S. Cobertura do solo e qualidade ambiental urbana como subsídios ao planejamento da paisagem. In: CONGRESO IBEROAMERICANO DE ESTUDIOS TERRITORIALES Y AMBIENTALES (CIETA), v.6, 2014, São Paulo, SP. Anais... São Paulo: USP, 2014. Artigos, p. 2886- 2902.

$\mathrm{NUCCI}$, J. C. Qualidade Ambiental e Adensamento Urbano: um estudo de ecologia e planejamento da paisagem do distrito de Santa Cecília (MSP). São Paulo: Humanistas/FFLCH/USP. 2001, 236p.

Qualidade ambiental e adensamento urbano: um estudo de ecologia e planejamento da paisagem aplicado ao distrito de Santa Cecília (MSP). Edição do Autor, 2008. Disponível em: https://tgpusp.files.wordpress.com/2018/05/qualidade-ambiental-e-adensamento-urbano-nucci2008.pdf. Acesso em: 22 ago. 2019.

OLIVEIRA, D. Curitiba e o mito da cidade modelo. Curitiba: Editora da Universidade Federal do Paraná, 2000, 203p.

PAULEIT, S.; BREUSTE, J. H. Land-Use and Surface-Cover as Urban Ecological Indicators. In: NIEMELÄ, JARI (Org.). Urban Ecology. Patterns, processes and applications. New York: Oxford University Press, 2011, 374p. https://doi.org/10.1093/acprof:oso/9780199563562.003.0004

PAZ, O. L. S.; NUCCI, J. C.; VALASKI, S. Cobertura da terra e Qualidade Ambiental do bairro Tatuquara. Curitiba/Paraná. GEOGRAPHIA OPPORTUNO TEMPORE, v. 1, p. 10-21, 2015. Disponível em: http://www.uel.br/revistas/uel/index.php/Geographia/article/view/31622/22339. Acesso em:12 out. 2019.

Mapeamento da Cobertura da Terra e da Qualidade Ambiental do Bairro Boa Vista (Curitiba/PR) por meio de imagens disponibilizadas pelo Google Earth e com o uso do software livre. In: SIMPÓSIO BRASILEIRO DE SENSORIAMENTO REMOTO, 17, 2015, João Pessoa. Anais... São José dos Campos: Instituto Nacional de Pesquisas Espaciais, 2015. Disponível em: http://www.dsr.inpe.br/sbsr2015/files/p0099.pdf. Acesso em: 12 out. 2019.

PIVETTA, A.; CARVALHO, J.A.; DALBEM, R.P.; MOURA, A.R; NUCCI, J.C. Sistema de classificação da cobertura do solo para fins de comparação entre cidades e bairros. XI SIMPÓSIO BRASILEIRO DE GEOGRAFIA FÍSICA APLICADA. Anais ... São Paulo: DG-USP, 2005.

ROCHA, M. F.; NUCCI, J. C. Índices de vegetação e competição entre cidades. Geousp - Espaço e Tempo (Online), v. 22, n. 3, 2018, p. 641-655. Disponível em: <https://www.revistas.usp.br/geousp/article/view/133554. Acesso em: 04 jul. 2020. https://doi.org/10.11606/issn.2179-0892.geousp.2018.133554

SPIRN, A.W. O jardim de granito. São Paulo: Edusp, 1995, 345p.

SUKOPP, H; WERNER, P. Naturaleza en las ciudades. Madrid: Mopt, 1991.

TAN, P. Y.; ZHANG, J.; MASOUDI, M.; ALEMU, J. B.; EDWARDS, P. J.; GRÊT-REGAMEY, A.; RICHARDS, D. R.; SAUNDERS, J.; SONG, X. P.; WONG, L. W. A conceptual framework to untangle the concept of urban ecosystem Services. Landscape and Urban Planning 200, 2020. Disponível em: https://doi.org/10.1016/j.landurbplan.2020.103837. Acesso em: 03 jul. 2020.

TONETTI, E. L. Potencialidades de Adensamento Populacional por Verticalização das Edificações e Qualidade Ambiental Urbana no Município de Paranaguá, Paraná, Brasil. Tese (Doutorado em Geografia) - Setor de Ciências da Terra, Universidade Federal do Paraná. Curitiba, 2011, 235p. Disponível em: http://hdl.handle.net/1884/255333. Acesso em: 30 set. 2019.

Caminhos de Geografia $\quad$ Uberlândia-MG $\quad$ v. 22, n. $80 \quad$ abr./2021 $\quad$ p. 153-168 Página 167 
VALASKI, S. Estrutura e Dinâmica da Paisagem: Subsídios para a participação popular no desenvolvimento urbano do município de Curitiba - PR. Tese (Doutorado em Geografia) - Setor de Ciências da Terra, Universidade Federal do Paraná. Curitiba, 2013, 144p. Disponível em: http://hdl.handle.net/1884/31669. Acesso em: 18 set. 2019.

Recebido em: 14/05/2020

Aceito para publicação em: 07/07/2020 